\title{
Fine Structural changes of fluid catalytic catalysts and characterization of coke formed resulting from heavy oil devolatilization
}

Ye Shui Zhang*, Xuekun Lu, Rhodri E. Owen, George Manos, Ruoyu Xu, Feng Ryan Wang, William C. Maskell, Paul R. Shearing, Dan J. L. Brett*

Electrochemical Innovation Lab (EIL), Department of Chemical Engineering, University College London, Torrington Place, London, WC1E 7JE

( ${ }^{\star}$ Corresponding author: d.brett@ucl.ac.uk, p.shearing@ucl.ac.uk)

\begin{abstract}
Coke formation from heavy oil cracking and the associated change in the porous structure of fluid catalytic cracking (FCC) catalysts has been studied using a comprehensive range of techniques, including 2D and 3D imaging and carbon/coke characterization techniques. The carbon/coke formed from heavy oil devolatilization has been investigated with a range of oilto-FCC catalyst ratios $(1: 3,1: 2,1: 1,2: 1$ and $3: 1)$ to simulate the ageing of FCC catalysts in an operating oil refinery. Carbon/coke was formed on all used FCC catalyst samples and was found to generally increase in quantity with the increasing oil-to-FCC catalyst ratios. Coke formation has been correlated with the observed porosity change of the FCC catalyst. Higher quantities of carbon/coke formed on the FCC catalyst due to higher oil-to-FCC catalyst ratios (simulated increase in time on-stream) leads to a decrease of total pore volume and surface area. X-Ray computed tomography (X-Ray CT) studies allowed 3-dimensional imaging of used catalyst particles and showed that the zeolite component of the FCC catalyst remains evenly distributed throughout the FCC particle from the centre to the exterior for pristine and used FCC catalyst particles. This technique showed that while the interior porous structure of the FCC catalyst particle is not affected by the coking, the exterior porous structure is substantially modified for all used FCC catalyst samples. This process of pore collapse and/or clogging at the surface of the particles is likely to have a significant effect on the deactivation of FCC catalysts that is commonly observed. The deeper insight into this process gained through this study is important for understanding how FCC catalysts change with time-onstream and eventually deactivate and may allow for future catalysts to be developed that are more resistant to deactivation.
\end{abstract}

Keywords: FCC; Heavy oil; Devolatilization; X-ray computed tomography 


\section{Introduction}

Fluid catalytic cracking (FCC) is one of the most effective and important industrial catalytic reaction processes for the conversion of heavy fractions of heavy oil into higher value transportation fuels and chemical feedstocks [1]. It is the chemical process used to crack relatively low-value heavy hydrocarbon molecules into lighter hydrocarbons which are more valuable, such as gasoline and propylene [2-4]. Catalysts play an important role in FCC processes, allowing targeted production of the more heavily used lighter hydrocarbons. Typical FCC catalysts consist of zeolite and clay with some binders and impurities.[2, 5-11] Ultrastable Y-zeolite [12] is the active phase in FCC catalysts. USY is Y zeolite that has been exposed to relatively mild hydrothermal treatment under control conditions in order to enhance its stability and avoid structure collapse during the regeneration stage of the FCC process. The hydrothermal treatment of the parent $Y$ zeolite of faujasite structure enables the controlled extraction of $\mathrm{Al}$ from the the zeolitic framework and hence generation of intracrystalline mesopores where the extracted $\mathrm{Al}$ resides as extra-framework $\mathrm{Al}$, avoiding structural collapse [13-15].

Kaolin clay with some impurities (such as $\mathrm{TiO}_{2}$ ) after calcination is the functional matrix of the FCC catalyst that is non-active amorphous aluminosilicate [15]; the binder being either alumina, silica or a mixture of both [5]. For the FCC process, the catalyst particles are usually $50-100 \mu \mathrm{m}$ in diameter and consist of a hierarchically porous structure containing micropores ( $<2 \mathrm{~nm}$ diameter) of active zeolite phase, mesopores ( $<50 \mathrm{~nm}$ diameter) and macropores ( $>50$ $\mathrm{nm}$ ) of the clay matrix $[16,17]$. The cracking of the heavy oil feedstock occurs in the active phase of the FCC catalyst, which needs to be accessible to heavy molecules. To encourage the cracking of the heavy molecules as much as possible, the hierarchical porosity of FCC catalyst is extremely important in the FCC process $[11,18,19]$. The FCC catalyst is also designed to possess good attrition resistance and hydrothermal stability of the active zeolite composite in the harsh high-temperature environment of the FCC process [20, 21].

In the continuous industrial FCC process, the structure of FCC catalyst changes over time due to the prolonged exposure to heavy oil at temperatures between $500-750{ }^{\circ} \mathrm{C}$ and steam exposure during the regeneration at even higher temperature [11, 22]. This can result in pore structure collapse, pore-clogging by carbon deposition and accumulation of metal contaminants from the feedstock (such as sodium, nickel, calcium, vanadium and iron); these factors can reduce the accessibility of molecules to the active sites and therefore reduce the cracking efficiency [5, 22-25]. The coke deposition, metal poisoning and structural changes of single FCC catalyst particles have been studied by many researchers using state-of-the-art microscopy and three-dimensional tomography [2, 4, 5, 22, 26, 27]. Liu et al. [2] studied the three-dimensional structure and composition change of single FCC catalyst particles using X- 
ray nanotomography, with a spatial resolution of $\sim 100 \mathrm{~nm}$. The authors developed a macropore network model to describe the resistance to mass transport through the FCC catalyst particle resulting from metal accumulation. Meirer et al. [4] mapped the nickel and iron poisoning of a single FCC catalyst particle by using X-ray nanotomography at a voxel size of $\sim 70 \mathrm{~nm}$. The authors found both nickel and iron accumulated at the outer layer of the catalyst particle, leading to a dramatic decrease of porosity and permeability. Krumeich et al. [5] studied the structural changes of a single FCC catalyst particle using scanning electron microscopy and elemental mapping techniques. The progressive structural change and chemical makeup of FCC catalyst particles have been investigated from micro to nanoscale. The authors found no change for the interior of a deactivated porous catalyst particle, which maintains the structure in the pristine catalyst. A single deactivated catalyst particle had a dense amorphous silica-alumina envelope around it, with depth to a maximum of $\sim 2 \mu \mathrm{m}$. The porosity of the catalyst particle decreases with the degree of catalyst structural degradation. They found that iron and nickel accumulated during the FCC process, causing the irreversible blockage of the pores which directly reduces the activity of the FCC catalyst $[4,27]$. Ihli et al. [22] recently performed a more comprehensive study of deactivated FCC catalyst particles by using ptychographic tomography (pixel size at $\sim 21 \mathrm{~nm}$ ), diffraction, fluorescence tomography and electron microscopy; they concluded that zeolite amorphization and porous structural changes occurring in the exterior of the FCC catalyst particle are the driving forces of the FCC catalyst deactivation. The formation of dense amorphous silica-alumina layer/shell on the exterior of FCC catalyst particles restrict mass transport to interior active sites of the catalyst, which would be expected to significantly reduce the catalytic activity.

The chemistry of the FCC catalyst, such as amorphization of the active zeolite composite, and structural changes occurring during deactivation due to the framework collapse and coking, still need to be investigated in-depth in order to improve future catalyst synthesis and reactor development. A fundamental understanding of the FCC catalyst deactivation behaviour, particularly that caused by structural changes occurring during heavy oil cracking process, is essential across all length scales [5, 28]. The FCC catalytic activity has been shown to be directly affected by the pore size distribution (PSD), pore surface area and the zeolite accessibility, and as such, the pore structure degradation of FCC catalyst remains a topic of immediate importance for researchers [1, 22, 27, 29]. Although some researchers have completed studies focused on the metal poisoning and structural changes of deactivated FCC catalyst, few of them have included characterisation of any carbon species on the FCC catalyst and related structural changes with coke/carbon formation. The present work focuses on the study of structural changes in terms of porosity and composition of the FCC catalyst and correlates them with coke/carbon formation. 


\subsection{Materials}

The UN1267 petroleum heavy oil used for this study was obtained from Roemex Ltd. It is solid at room temperature with a black or dark brown colour. The American Petroleum Institute [30] gravity of the heavy oil sample used for this work is $29.9^{\circ}$, which was calculated by the reported formulas [31]. The elemental analysis for heavy oil was obtained from SOCOTEC, UK, that the sample contains $85.87 \%$ of carbon, $13.84 \%$ of hydrogen, $0.23 \%$ of sulphur and $0.14 \%$ of nitrogen. The heavy oil sample contains $47.78 \%$ of saturates, $23.78 \%$ of aromatics, $17.79 \%$ of resins and $10.65 \%$ of asphaltenes that was analysed by Jones Environmental, UK. The fluid catalytic cracking [32] catalyst is the same as that previously reported by Lettieri et al. [33] as FCC1; the zeolite content is $5 \%$ and density is $1420 \mathrm{~kg} \mathrm{~m}^{-3}$. Pore size distribution and the powder preparation procedure are also reported. The FCC catalysts were obtained by riffling large batches, and small quantities were also riffled for characterizing the particle physical properties [34, 35]. The morphology of the FCC catalyst is shown in Figure 1. particle diameter is between 30-60 $\mu \mathrm{m}$, with an imperfect spherical shape. The FCC catalyst sample was kept in an oven, held at $130^{\circ} \mathrm{C}$ for at least $48 \mathrm{~h}$ before experiments to remove moisture.

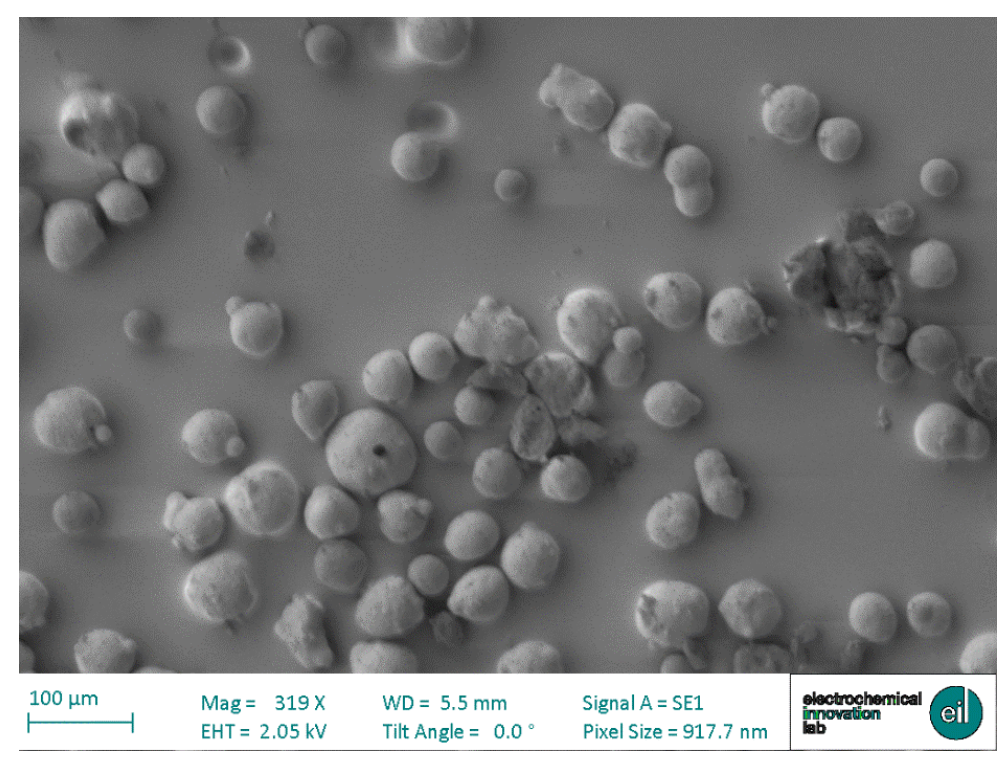

Figure 1 SEM image of fresh FCC catalyst.

\subsection{Experimental set-up.}

Figure 2 shows a schematic diagram of the experimental set-up used for heavy oil devolatilization experiments in the presence of FCC catalyst designed to emulate the FCC catalyst deactivation in an industrial process. Increasing oil-to-FCC catalyst ratios of 1:3, 1:2, $1: 1,2: 1$ and $3: 1$ were employed to simulate progressive FCC catalyst ageing on-stream in a continuous industrial process by exposure to increasing quantities of heavy oil. 
The mass of FCC catalyst was constant at $0.5 \mathrm{~g}$ for each experiment. FCC catalyst and oil samples were placed in a ceramic crucible, which was contained within a quartz tube reactor with an inner diameter of $6.5 \mathrm{~cm}$ and $85 \mathrm{~cm}$ in length. The quartz tube/reactor was heated externally by a tubular furnace. Nitrogen was used as a carrier gas with a continuous flow of $200 \mathrm{ml} \mathrm{min}{ }^{-1}$ during the experiment. The furnace was heated at $10^{\circ} \mathrm{C} \mathrm{min}-1$ to $500^{\circ} \mathrm{C}$ and held for $30 \mathrm{~min}$. This time was found to be sufficient to ensure full decomposition of feedstock. All of the produced gas and volatiles were flushed out to the ventilation system. For all experiments, the system was purged with nitrogen at $200 \mathrm{ml} \mathrm{min}^{-1}$ for $30 \mathrm{~min}$ prior to the test to remove the air inside the quartz tube/reactor.

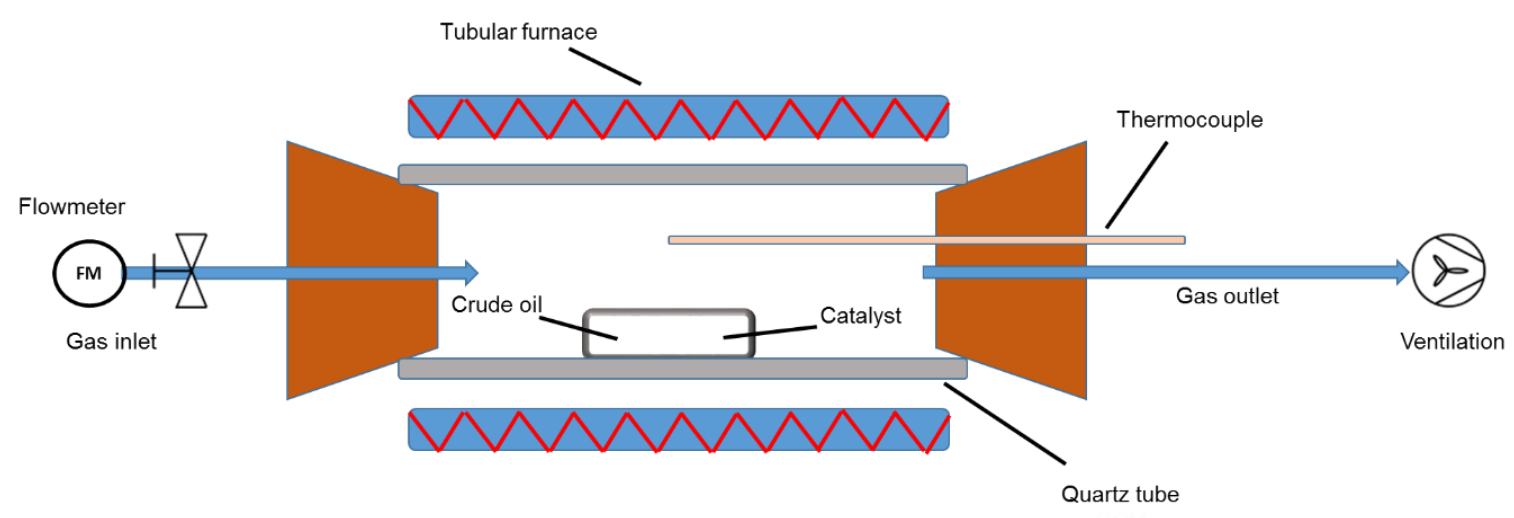

Figure 2 Schematic diagram of the batch reactor for heavy oil devolatilization in presence of FCC catalyst.

\subsection{Characterization methods}

Thermal gravimetric analysis. The FCC catalysts were analysed through temperature programmed oxidation (TPO) by using a Perkin Elmer Pyris 1 thermal gravimetric analyzer (TGA). Similar amounts (approximately 4-8 mg) of each FCC catalyst were placed in the sample crucible, which was heated to $900{ }^{\circ} \mathrm{C}$ under a flow of $20 \mathrm{ml} \mathrm{min}^{-1}$ of air with a ramp rate at $10^{\circ} \mathrm{C} \mathrm{min}^{-1}$. By comparing the different oxidation characteristics of the FCC catalysts, the results enable the identification of the different phases of carbon/coke present, based on the differing thermal stability of the two types of carbon/coke depositions. Amorphous carbon is oxidized at a lower temperature $\left(<600^{\circ} \mathrm{C}\right)$, compared with the graphitic carbon, since the latter filamentous carbon has higher thermal stability [36-41].

Scanning electron microscopy. A Zeiss EVO 10 scanning electron microscope (SEM) was used to characterize the fresh FCC catalyst to estimate the particle size. This is a widely applied technique for observing morphology, crystallites and surface texture of materials.

Raman spectrometry. A Thermo Scientific DXR Raman spectroscope with a wavelength of $514 \mathrm{~nm}$ was used for Raman analysis. Spectra were recorded between 100 and $3500 \mathrm{~cm}^{-1}$ 
with a laser power of $10 \mathrm{~mW}$. For each sample, three spectra were recorded, with an acquisition time of $60 \mathrm{~s}$. Results were used to indicate the degree of graphitization of the carbon formed. Raman spectroscopy is a technique regularly used to characterize the structures of carbon/coke materials, including the amorphous and/or graphitic carbons [42-46]. The $D$ and $G$ bands of the Raman spectra were fitted with Gaussian shaped bands using OriginPro software and were used to calculate the relative intensities of the two peaks as is commonly reported in the literature. [47-49]

X-ray computed tomography. Non-destructive X-ray computed tomography (CT) was undertaken on a Zeiss Xradia Ultra 810 X-ray microscope. A single catalyst particle was mounted onto the tip of a pin using epoxy and aligned within the X-ray beam. The Ultra 810 uses a quasi-monochromatic beam at $5.4 \mathrm{keV}$ from a $\mathrm{Cr}$ rotating anode source; its focusing optics provide a field-of-view (FOV) of $63 \times 63 \mu \mathrm{m}^{2}$, and a corresponding voxel size of $\sim 63$ $\mathrm{nm}$ in large field-of-view (LFOV) mode. X-ray projections were collected every $60 \mathrm{~s}$ during angular rotation through $180^{\circ}$ with a step size of $0.14^{\circ}$, giving 1301 projections over the full $180^{\circ}$ scan. These radiographic projections were then reconstructed by a standard filtered back projection algorithm in the Zeiss Xradia XMReconstructor software [50]. Post-processing of the reconstructed CT data was conducted using Avizo 9.4 (Thermo Fisher Scientific, UK). Continuous pore size distribution (C-PSD) developed by Munch et al. [51] was used for the pore phase analysis in open source software (Fiji).

Physical adsorption and desorption. The porous properties of the catalysts were determined by measuring the nitrogen adsorption and desorption isotherms from the catalyst at equilibrium vapour pressure using the static volumetric method. Nitrogen adsorptiondesorption isotherms were recorded at $77 \mathrm{~K}$ using a Micromeritics 3Flex surface characterization analyser. The samples were degassed at $300^{\circ} \mathrm{C}$ overnight. Specific surface areas were determined according to the Brunauer, Emmett and Teller (BET) model [52, 53], with pore diameters, volumes and distributions determined through Barrett-Joyner-Halenda (BJH) analysis [54].

\section{Results and discussion}

\subsection{Coke characterization of reacted FCC catalysts}

The amount of carbon/coke formed on FCC catalyst in heavy oil devolatilization process was quantified by temperature programmed oxidation (TPO). Figure 3(a) shows the TPO results of the FCC catalyst devolatilization with different oil-to-FCC ratios $(1: 3,1: 2,1: 1,2: 1$ and 3:1). The weight loss in the TPO thermogram is due to the oxidation of deposited carbon/coke on the FCC catalyst. The results show that carbon/coke was formed on all of the FCC catalysts, 
regardless of the oil-to-FCC catalyst ratio. Figure 3(b) shows that carbon/coke formation on FCC catalysts increases with the oil-to-FCC ratio, the highest amount of carbon/coke formed observed was 10.1 wt.\% for the 3:1 ratio. These results show that as the carbon input increases (representative of longer time-on-stream), more carbon/coke is formed.

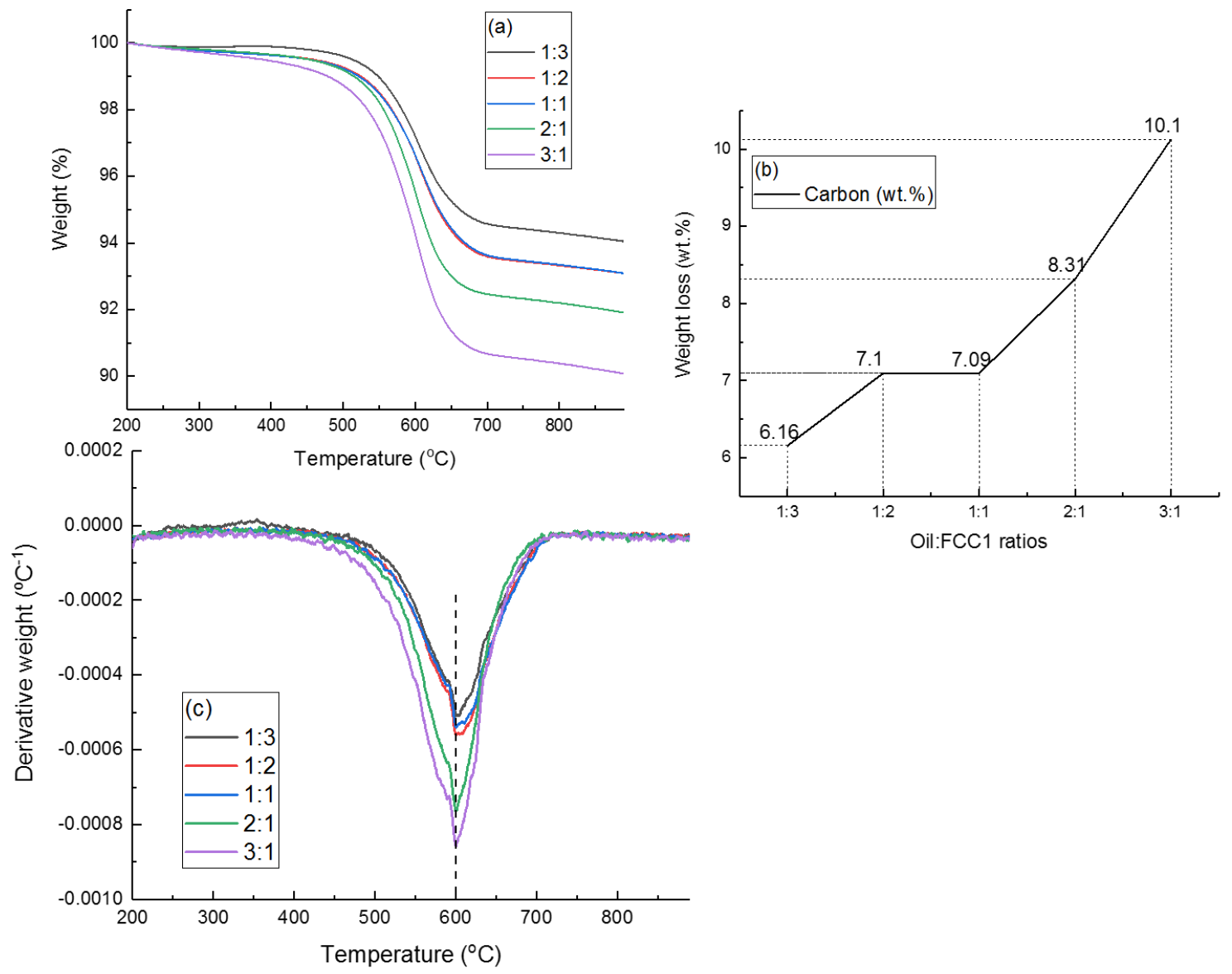

Figure 3 (a) TPO of carbon/coke deposited on FCC catalyst from heavy oil at $500{ }^{\circ} \mathrm{C}$ with oilto-FCC ratios of 1:3, 1:2, 1:1, 2:1 and 3:1; (b) quantified carbon formed on each FCC catalyst based on TPO weight loss; (c) DTG-TPO results of carbon/coke produced from oil at $500{ }^{\circ} \mathrm{C}$ in presence of FCC catalyst with oil-to-FCC ratio of $1: 3,1: 2,1: 1,2: 1$ and $3: 1$.

The peaks in the derivative thermogram as shown in Figure 3(c) are all at temperatures around $610^{\circ} \mathrm{C}$, indicating that the carbon/coke formed at different oil-to-FCC ratios have a similar degree of graphitization. These results are in agreement with previously reported work [36, 55] that show that an increase of feedstock will increase the carbon/coke formation without any effect on the degree of graphitization.

The broad oxidation peaks in Figure 3(c) are due to two overlapping oxidation peaks for each sample, consistent with two types of carbon being oxidized at different temperatures. There is a peak at lower temperature, corresponding to oxidation of amorphous carbon, and a peak at 
higher temperature corresponding to oxidization of graphitic carbon [36, 38-41]. These results are further confirmed by the Raman analysis, as shown in Figure 4. The D-band indicates the disordered carbon, while the G-band indicates the graphite carbon [43]. The intensity ( $I$ ) of each peak and the ratio of the two peak intensities $I_{D} / I_{G}$ is used to determine the degree of graphitization of the carbon structure [36]. All the carbon/coke samples formed on FCC catalyst at $500{ }^{\circ} \mathrm{C}$ with different oil-to-FCC ratios possess a D-band at $1375 \mathrm{~cm}^{-1}$ and a Gband at $1590 \mathrm{~cm}^{-1}$. The degree of graphitization of the coke formed on the catalyst at different oil-to-FCC ratios are similar, with $I_{D} / I_{G}$ ratios in a relative narrow range between 0.539 and 1.06, as shown in Figure 4(b).

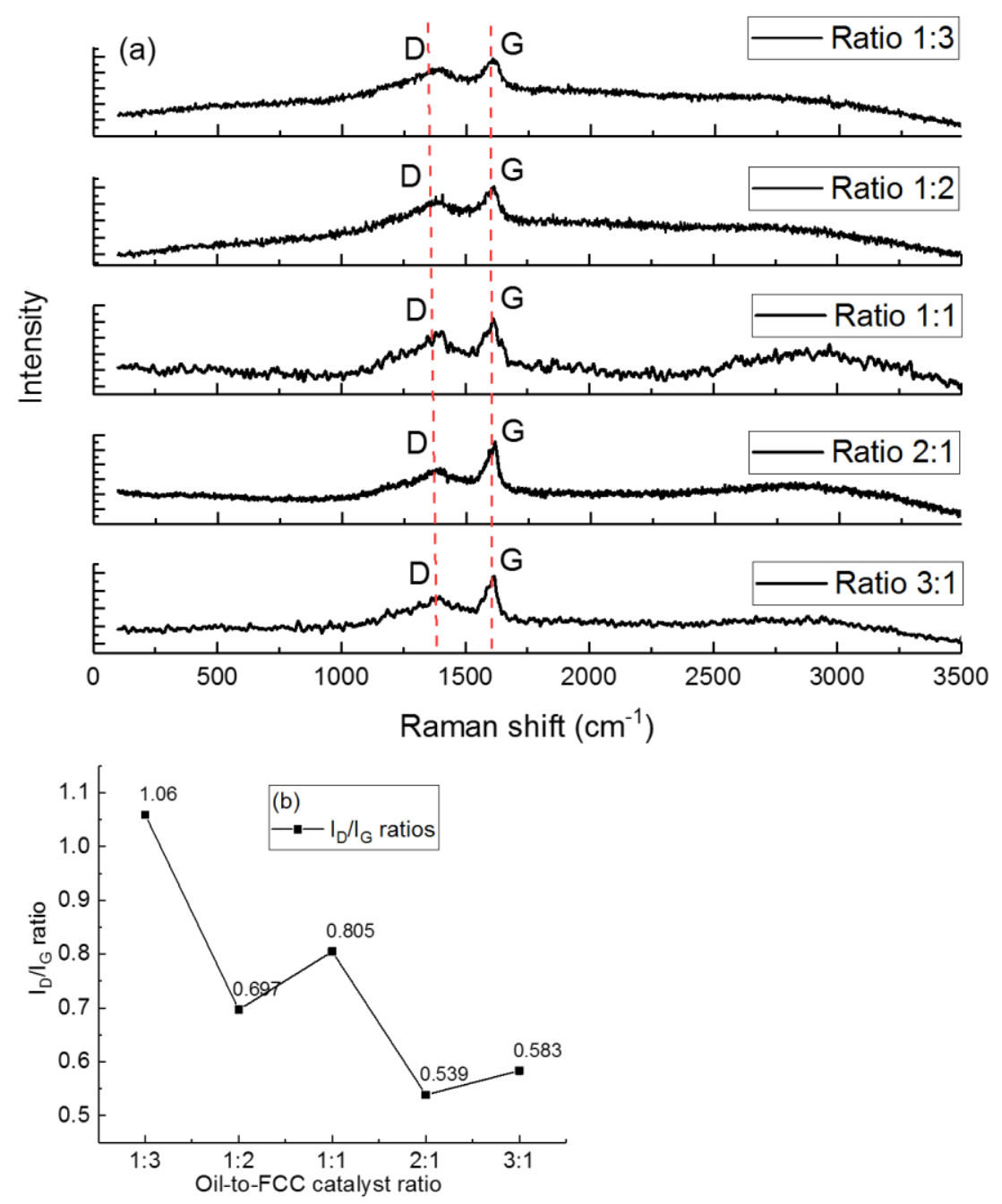

Figure 4(a) Raman spectra obtained for each of the FCC samples showing peaks attributed to the carbon/coke produced from oil at $500{ }^{\circ} \mathrm{C}$ with oil-to-FCC ratio at 1:3, 1:2, 1:1, 2:1 and $3: 1 ;$ (b) $I_{D} / I_{G}$ ratio.

Scanning electron microscopy (SEM) was used as a two-dimensional micro-scale characterization method to investigate the surface morphology change of the FCC catalyst 
after the oil devolatilization reaction. SEM micrographs of a pristine FCC catalyst particle and used catalysts reacted at different oil-to-FCC catalyst ratio are shown in Figure 5. Figure 5(a) shows the smoother surface of the pristine FCC catalyst relative to the used FCC catalysts (Figure 5(b) - (f)) all with peeled and rougher surface compared to the pristine FCC catalyst. The rougher surface can be attributed to the carbon/coke formation on the FCC catalyst surface identified in the TGA and Raman studies. The rough surface of the FCC catalysts could also be attributed to collapsing of the surface porous structure and blockage of the external surface pores.
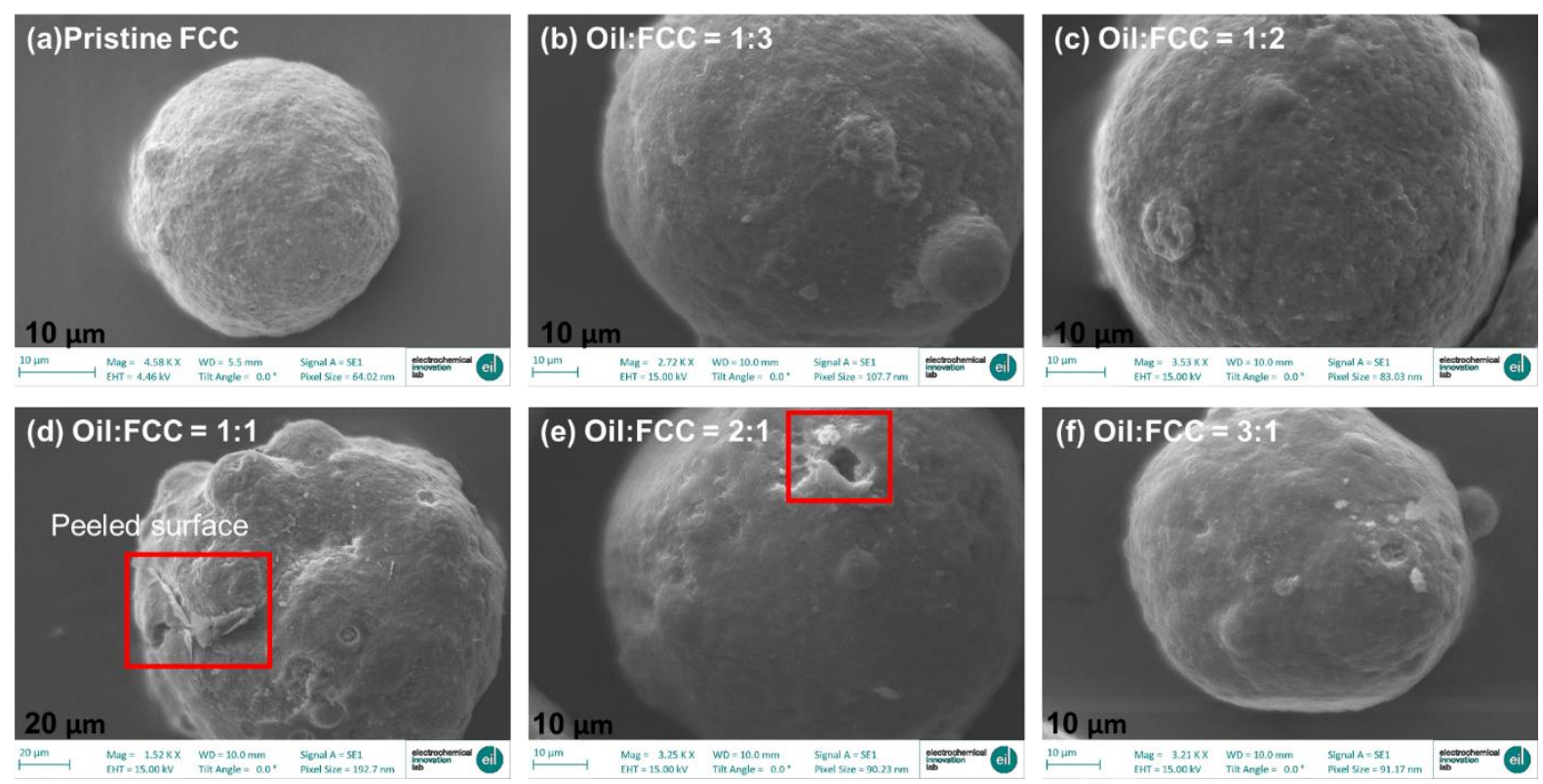

Figure 5 Scanning electron microscopy micrographs of a pristine FCC particle, and used FCC particles (reacted with oil-to-FCC ratios of 1:3, 1:1, 2:1 and 3:1).

\subsection{Structural change of reacted FCC catalyst}

To clarify the morphology and internal structural changes of the FCC catalysts used, X-ray computed tomography (X-ray CT), was used identify any macroporous structure changes. [5, 56] Virtual slices and 3D volumes of the pristine FCC catalyst (oil-to-FCC ratio 1:3) are illustrated in Figure 6. The pore, clay and zeolite phases can be clearly identified according to their different densities, based on which the three phases were segmented for further radial distribution analysis. Figure 6 shows the zeolite highlighted in red, the clay in yellow and the pores in green. 

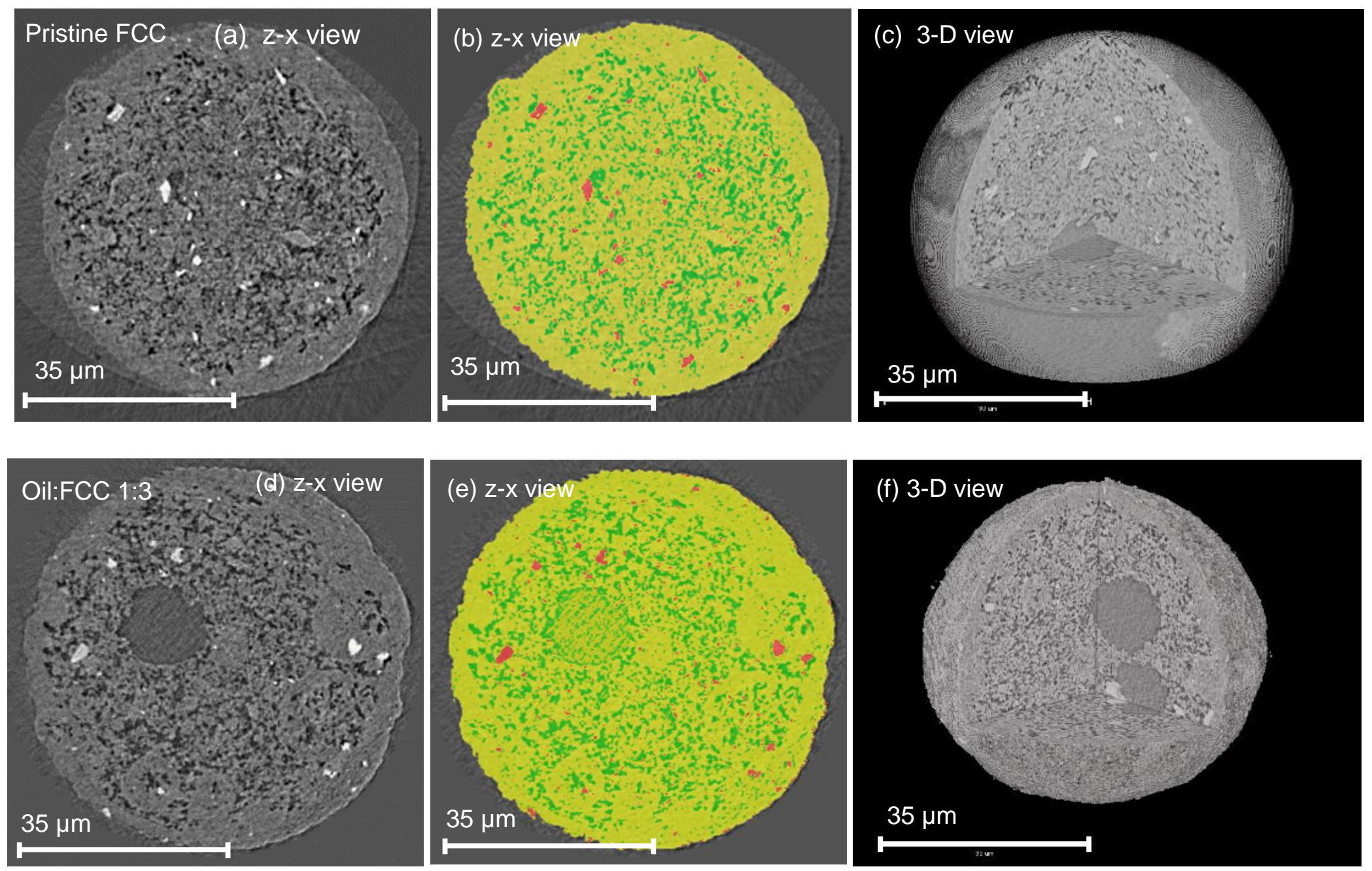

Figure 6 (a)-(c) Segmented tomograms of pristine FCC and (d)-(f) FCC with oil-to-FCC ratios at 1:3 (Z-X view: red denotes to zeolite, green denotes to pores and yellow denotes to clay). 
Figure 7 shows the radial distribution profiles of clay, pore and zeolite elements of pristine and used FCC catalysts with respect to the particle centre. The zeolite is evenly distributed from the centre of the catalyst particle to the exterior for both the used and pristine FCC catalysts. Figure 7(a) shows a drop in clay content at the surface of the pristine FCC catalyst particle, corresponding to a higher normalised fraction of pore. This indicates that the pristine FCC catalyst particle is more porous at the surface.
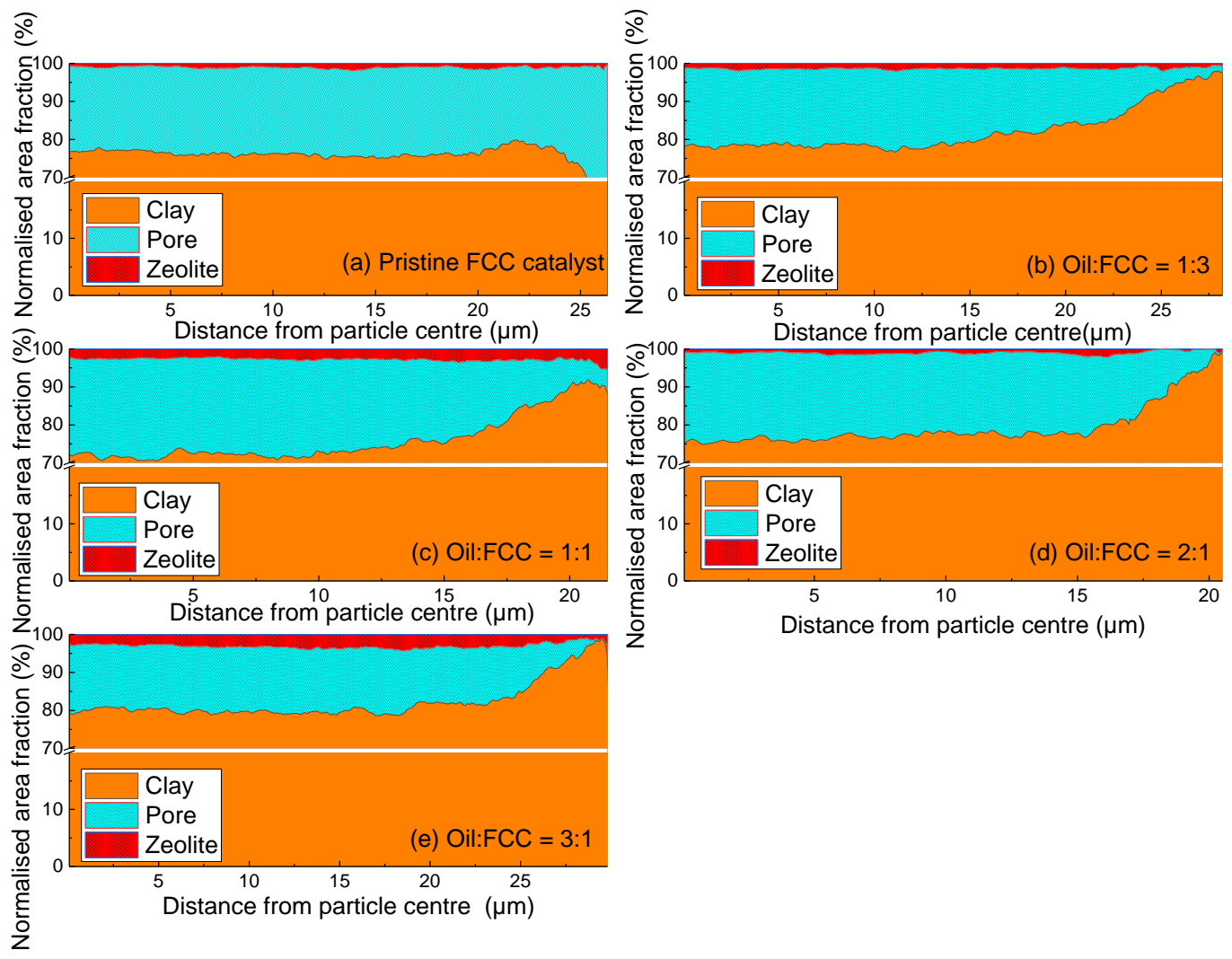

Figure 7 Radial distribution profiles of clay, pore and zeolite elements, with respect to the particle centre, of a pristine FCC particle (a), and used FCC catalyst particles, reacted with oilto-FCC ratios at 1:3 (b), 1:1 (c), 2:1 (d) and 3:1 (e), with respect to the particle centre.

Figure $7(b)$ - (e) show that the clay fraction of the FCC catalyst particle increases, while the pore fraction decreases near the external surface. This indicates that the porous surface structure 'collapses' at high temperatures and leads to pore blockage. Alternatively, the carbon/coke formation near the external surface might lead to pore-mouth blockage. The latter assumption is supported by the TGA results in Figure 3, showing that carbon/coke formation occurred within the FCC catalyst samples. However, the TGA cannot provide location-specific coke quantification within the FCC catalyst particles. The surface pore blockage may also be attributed to non-catalytic carbon/coke deposition formed directly from products of oil devolatilization. As in the pristine sample, the clay fraction stays constant in the core of the 
particle up to $\sim 20 \%$ of the radius from the external surface where it decreases steeply. This picture does not change with the oil-to-catalyst ratio, indicating that an almost complete porous mouth-blockage takes place relatively early, with no further significant effect. After the full blockage of the external surface pores, there seems to be no further porous structure changes with any additional heavy oil feeding.

Figure 8(a) and (b) visualises the 3D distribution of the zeolite in pristine and used FCC catalysts reacted with an oil-to-FCC ratio of 1:3, respectively. The zeolite shows an even distribution from the centre to the exterior of the FCC catalyst particle; the FCC catalyst presents a similar zeolite distribution to pristine FCC catalyst. The results are consistent with the normalised fraction of zeolite element, as shown in Figure 7(a) and (b). Figure 8(a) and (b) also shows that the zeolite components in both pristine FCC and used FCC catalyst particles are distributed randomly with irregular size and shape. Figure 8(c) shows the comparison of zeolite distribution for pristine and used FCC catalyst particles reacted with a range of oil-toFCC ratios. The results show that the distribution of features for pristine and used FCC catalyst samples are similar. The zeolite fragments in different shapes and sizes are distributed randomly from the particle centre to the exterior. The use of FCC particles as oil cracking catalysts has no significant effect on the distribution of zeolite itself.

(a) Pristine FCC

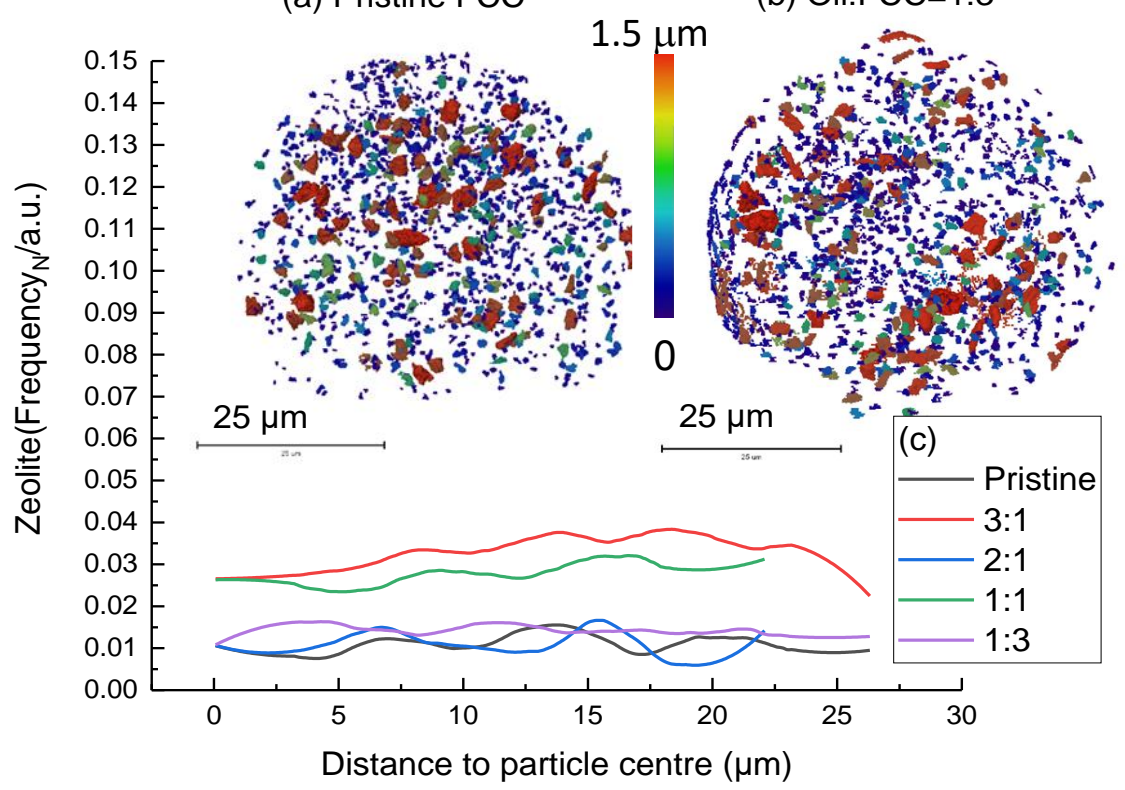

Figure 8 3D distribution of the zeolite for (a) the pristine and (b) used 1:3 (oil:FCC) sample, with colours mapping the size of zeolite fragments; (c) the volume fraction of zeolite measured along the radial direction from the particle centre. 
Figure 9 shows the radial distribution of clay and pore phases of pristine and used FCC catalyst particles from the particle exterior to the centre. Figure 9(a) clearly shows that the clay phase distribution generally decreases from the particle exterior to the centre for all used FCC catalysts (oil-to-FCC catalyst ratios at 3:1, 2:1, 1:1 and 1:2), but the pristine FCC catalyst shows an increase in clay fraction from the surface of the particle to the centre. Correspondingly, the pore distributions changes that occur to the FCC catalyst under different reaction conditions are shown in Figure 9(b). The largest deviations occur at the outer surface of the particles, up to depths of $\sim 7.5 \mu \mathrm{m}$. The distributions of clay and pore within the interior of the FCC particle remain unchanged regardless of the reaction conditions. These conclusions are in agreement with previous research carried out by Krumeichet al. [5], where the interior porous structure of the FCC catalyst particle is not affected by the degree of catalyst deactivation. The reason for the composition change on the outer surface of the FCC catalyst particle may be due to the higher concretion of the amorphous layer of aluminosilicate on the FCC catalyst particle surface which reduces the mass transport of the active sites of the particle, resulting in a reduction of the catalytic capacity [22]. Krumeich et al. [5] also found a similar result, that there is an amorphous silica-alumina 'envelope' formed on the outer surface of the FCC catalyst particle with a plateau at $\sim 2 \mu \mathrm{m}$.

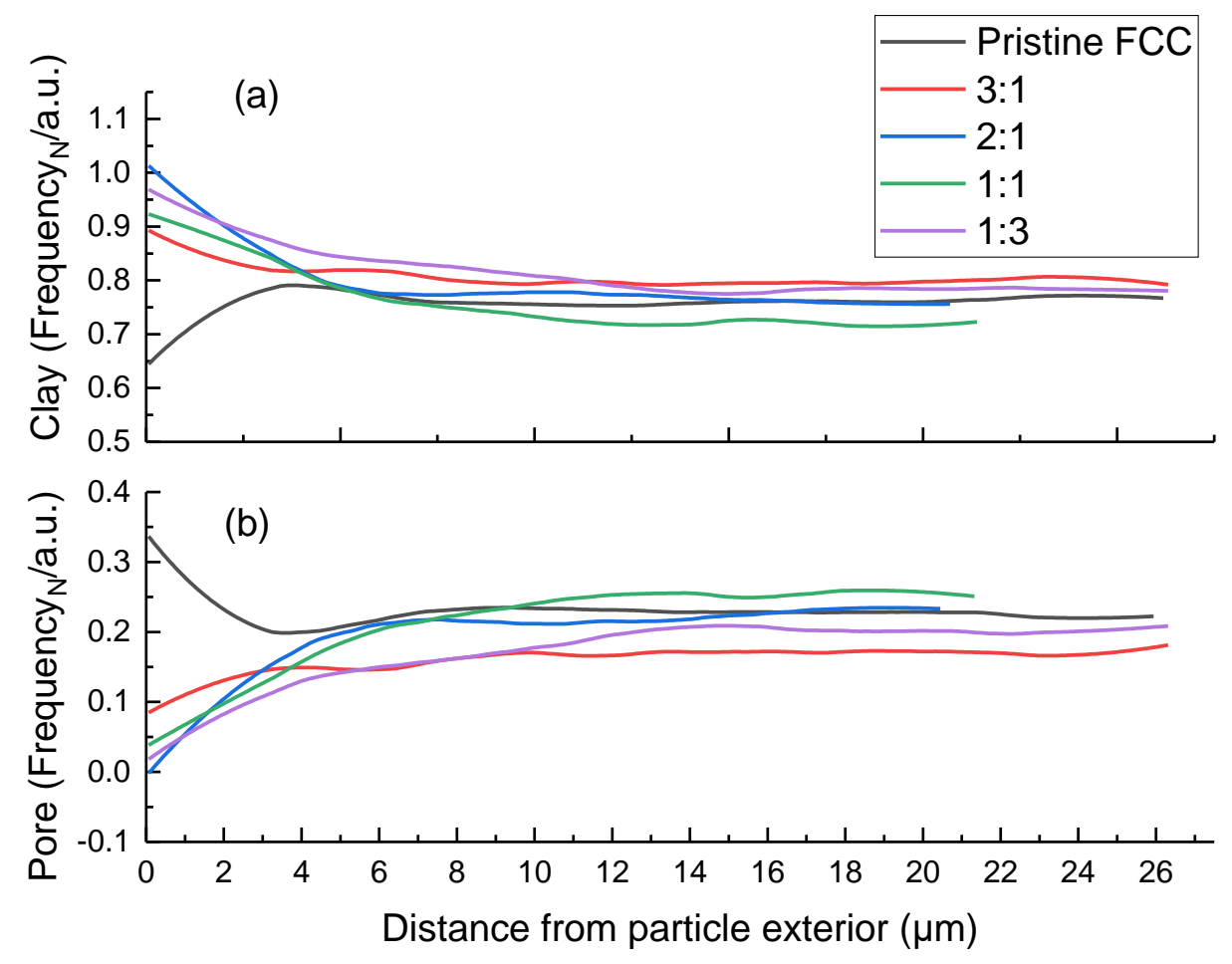

Figure 9 Radial distribution of (a) clay and (b) pore for pristine and used FCC catalyst particles with different oil-to-FCC catalyst ratios. 
Figure 10 shows the pore size distribution of single FCC catalyst particles for pristine and used FCC catalysts, obtained with different oil-to-FCC ratios. It is found that the pore size and volume of different samples follows a "Gaussian" distribution. The pores with the highest frequency have diameters in the region of $\sim 126-378 \mathrm{~nm}$, with the $\sim 126 \mathrm{~nm}$ pore size region being most prevalent. The pristine FCC catalyst has the highest number of relative small pores with diameter at $126 \mathrm{~nm}$ compared with the FCC catalysts after the reaction with different oilto-FCC catalyst ratios, As the distribution is relative, the catalyst samples show correspondingly the smallest number of the larger pores with diameter $\sim 378 \mathrm{~nm}$. Alternatively, this could be due to the reacted FCC catalyst with porous structure collapse potentially leading to larger pores than in the pristine FCC catalyst. Feedstock impurities encountered during operation, such as iron have also been shown to have a similar effect.[57] Other researchers hypothesised that the impurity-induced melting binder and matrix components close to FCC catalyst particle exterior may lead to catalyst deactivation by removing macro and mesoporosity [57]. 


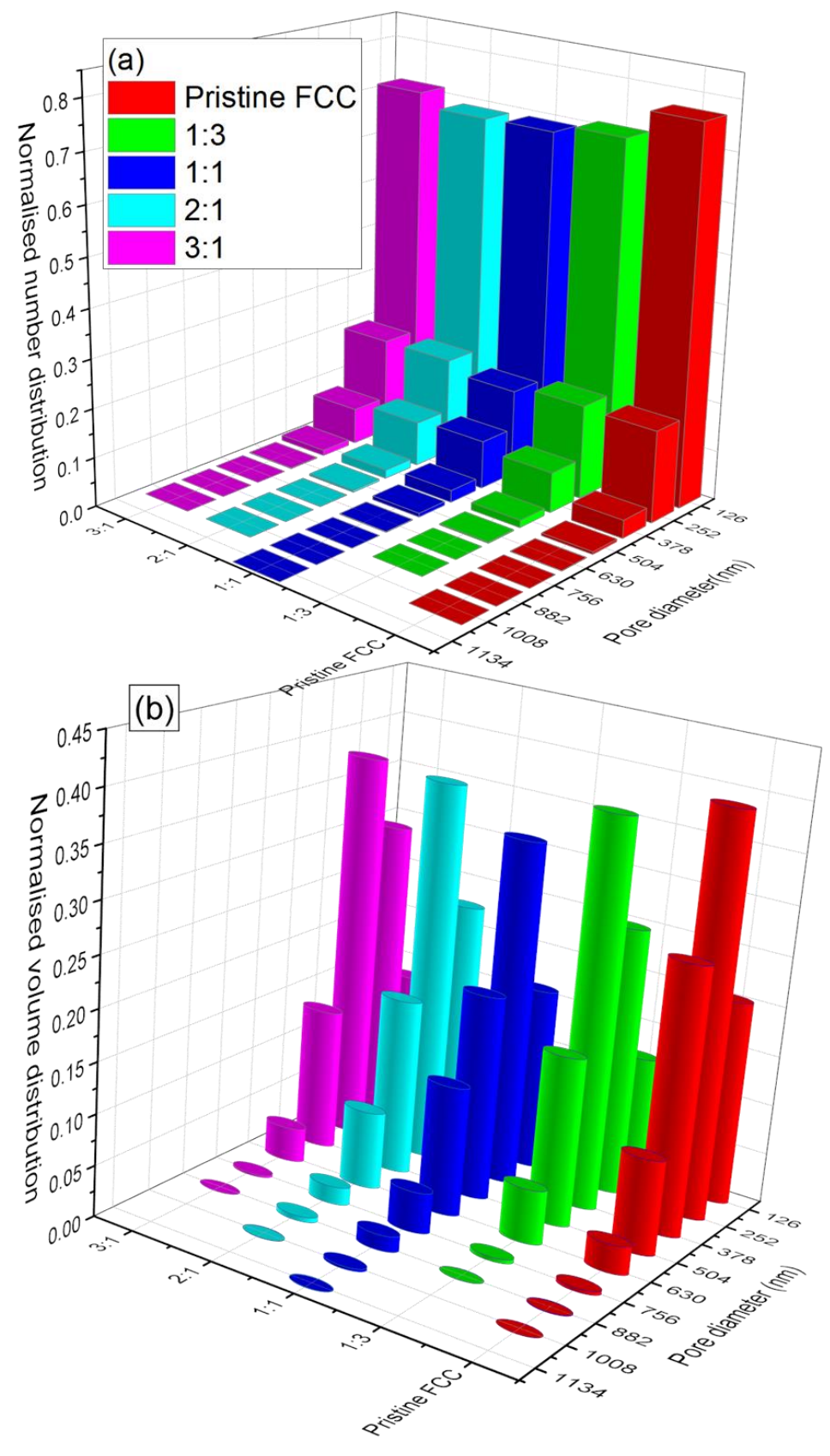

Figure 10 (a) Pore size and (b) volume distribution maps of pristine FCC and deactivated FCC with oi-to-FCC ratios of 1:3, 1:1, 2:1 and 3:1. 
While X-ray CT is a powerful tool for analysis of porous materials, giving vital information about the spatial distribution of the pores within a material, because of the limitation in spatial resolution of X-ray nano-CT scan ( $100 \mathrm{~nm}$ ) other techniques are more suited for studying the meso- and micro-pores of materials. In this study nitrogen physical adsorption and desorption, as shown in Figure 11 and Figure 12 respectively, were utilised to study the meso and micro-porosity of the FCC particles. All of the samples exhibited type IV or V isotherms according to the IUPAC classification, indicative of the presence of meso-pores within the FCC catalyst particles [58, 59]. There is no clear correlation between the oil-to-FCC ratio and mesoporous structure of FCC catalysts. The obvious hysteresis for all adsorption isotherms shown in Figure 11 may relate to the morphological properties of the sample, such as pore size distribution, pore geometry and connectivity of the porous materials, as has been reported previously [59]. The shape of the adsorption hysteresis loop exhibited an $\mathrm{H}_{3}$ shape, which indicates the porous material has slitshaped pores with two ends open, as classified by De Boer [59-61]. The slope associated with every hysteresis loop of the adsorption/desorption curves is related to the tensile strength effect $[58,59,62]$. The highlighted hysteresis curves shown in Figure 11 indicate the low-pressure hysteresis due to the volume change of the adsorbent. It may be caused by the swelling of the non-rigid pores in the FCC catalyst, or pores that have been occupied irreversibly by the similarly sized molecules [59, 63].

According to pore volume distributions for all FCC catalyst samples, illustrated in Figure 12, there are two peaks in the volume distribution curves. Figure 12(a) shows that peak B generally decreases with the incremental increase of oil-to-FCC catalyst ratio, except the 1:2 ratio. This could be due to the blockage of relatively large pores by carbon/coke; this assumption is supported by TPO results in Figure 3, which show that an increase of oil-to-FCC ratio leads to an increment of carbon/coke deposition on the FCC catalyst. Figure 12(b) shows peak $A$ at $3.9 \mathrm{~nm}$ and peak $B$ at $10.2 \mathrm{~nm}$ (red dotted line, Figure 11(b)), which indicates the presence of mesopores in all FCC catalyst samples 

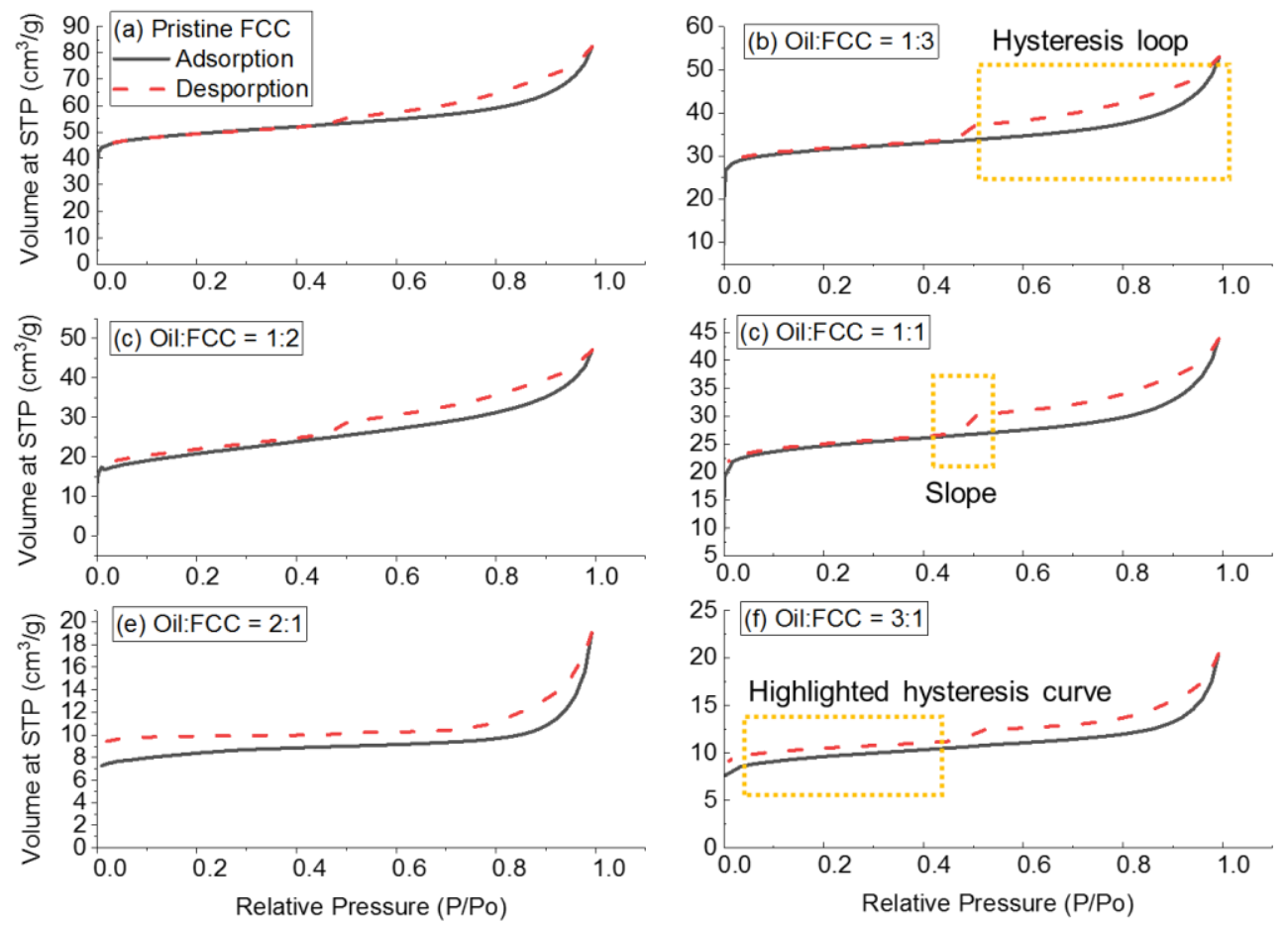

Figure 11 Nitrogen adsorption and desorption isotherms of pristine FCC and used FCC catalysts obtained with oil-to-FCC ratios of 1:3, 1:2, 1:1, 2:1 and 3:1.
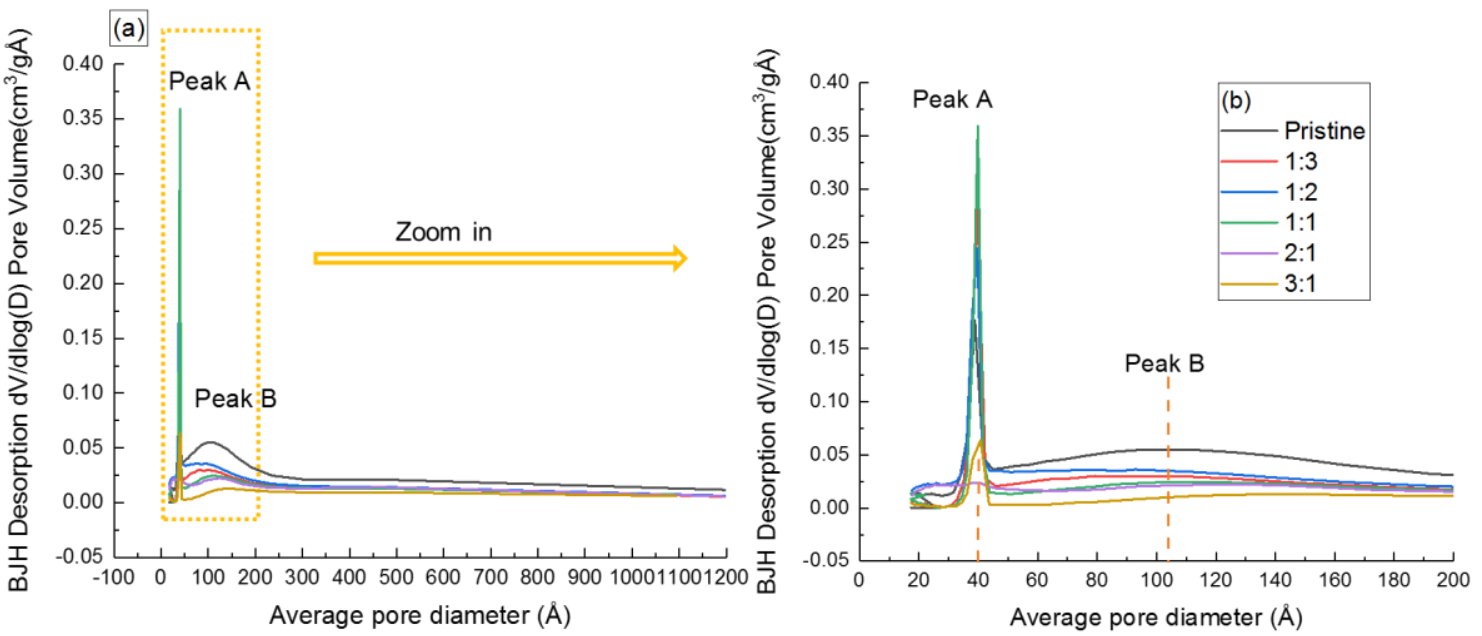

Figure 12 (a) Pore volume distribution of pristine FCC and used FCC catalysts obtained with oilto-FCC ratios of $1: 3,1: 2,1: 1,2: 1$ and $3: 1$; (b) zoom-in of peak $A$ and peak $B$. 
Figure 13 shows the BET surface area, total pore volume and BJH average pore diameter of all FCC catalyst samples. The BET surface area and total pore volume generally decrease with an increase of oil-to-FCC ratio, this is likely due to the increase of carbon/coke deposition during the devolatilization of the heavy oil sample, with higher ratios representing longer times on stream and as such exposure to greater quantities of oil. The more carbon/coke deposited on the FCC catalyst, the more the pores are blocked by the carbon/coke, resulting in a reduction of surface area and total pore volume. The assumption can also be supported by the TPO results in Figure 3 , which indicate that the increasing of oil-to-FCC catalyst ratio results in more carbon/coke deposition. Another contributing factor may be the collapse of the surface porous structure of the FCC catalyst and the amorphization of the surface crystalline zeolite that will form a shell on the surface particle to prevent the further porous structural change in the interior of the particle. This assumption is supported by the radial distributions of clay, pore and zeolite elements segmented by the X-ray CT results illustrated in Figure 7, where the surface porous structure of the FCC catalyst is greatly reduced after the heavy oil devolatilization. 

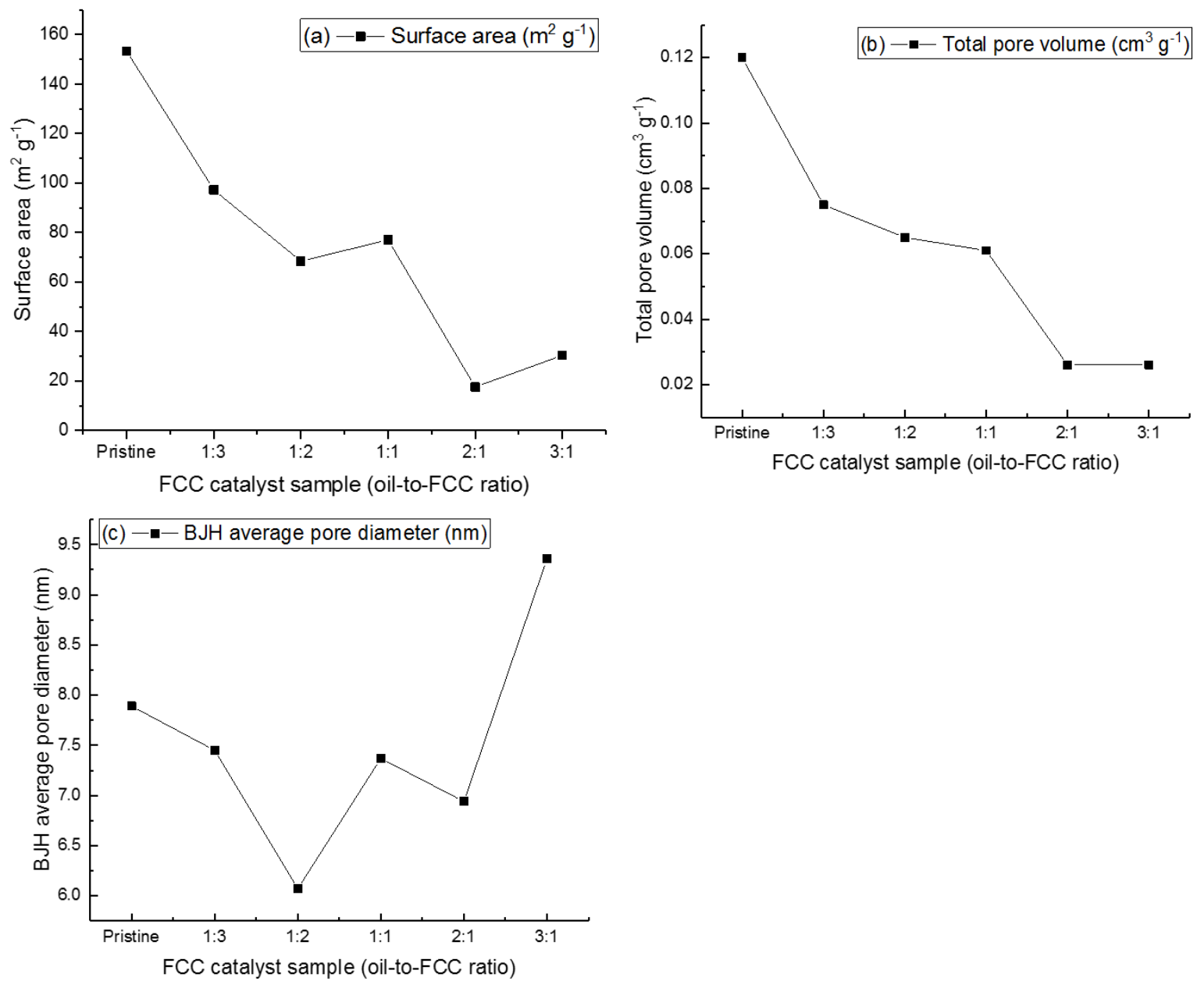

Figure 13 BET surface area, total pore volume and BJH average pore diameter of FCC catalysts (pristine FCC and FCC catalysts react with oil-to-FCC ratio at 1:3, 1:2, 1:1, 2:1 and 3:1) obtained from nitrogen adsorption and desorption isotherms.

\section{Conclusion}

The study investigates the structural changes of FCC catalyst particles and the coking on FCC catalyst from heavy oil volatilisation/decomposition using ultra-high-resolution X-ray computed tomography. The porosity and composition changes of FCC catalyst have been studied and correlated with carbon/coke formed after heavy oil volatilisation/decomposition.

Coke formed on all of the FCC catalyst particles after heavy oil volatilisation/decomposition regardless the oil-to-FCC ratio, where an increasing oil-to-FCC catalyst ratio generally results in an increase in the amount of carbon/coke formed. From differentiation of the formed coke oxidation results and Raman spectra results, it can be concluded that there was no significant 
difference for the degree of graphitization of the formed carbon/coke on FCC catalyst. As the heavy oil volatilisation/decomposition temperature was kept constant at $500{ }^{\circ} \mathrm{C}$ for every experiment.

The surface morphology and three-dimensional compositional changes of the FCC catalyst particles have also been studied by scanning electron microscopy and X-ray computed tomography. The FCC catalysts show a rougher surface compared with the pristine FCC catalyst. The compositional changes of pore, clay and zeolite from a single FCC catalyst particle's centre to the exterior have studied using X-ray computed tomography. The zeolite component is evenly distributed in the FCC catalyst particle from centre to the exterior of the particle, with no change observed between pristine and used catalysts. The porosity gradually decreases from the centre to exterior of the particle; correspondingly, an increase in clay fraction is observed. This could be caused by surface structure damage and the carbon/coke formed on the particles. These effects are most obvious at the outer surface of the particles at depths of up to $\sim 7.5 \mu \mathrm{m}$.

Characterisation of the structure of single FCC catalyst particles was performed using X-ray computed tomography. The FCC catalysts have fewer macro-pores compared with pristine FCC catalyst, an effect likely caused by the carbon/coking formed on FCC catalyst and the porous structure changes close to the surface of catalyst particles. The meso-porous structure was determined by nitrogen adsorption and desorption. The majority of the porous volume contribution is from meso-pores with a diameter $\sim 3.9 \mathrm{~nm}$, with a much smaller contribution from pores with a diameter of $\sim 10.2 \mathrm{~nm}$. The volume contribution from pore size at $\sim 10.2 \mathrm{~nm}$ generally decreased with an increase of oil-to-FCC ratio. The surface area and total pore volume of bulk FCC catalysts have also been obtained. The surface area and total pore volume reduce in the used FCC catalysts with an increase in the oil-to-FCC ratio.

\section{Acknowledgements}

This work is supported by Qatar National Research Fund (QNRF) from National Priority Research Program (NPRP9-313-2-135) and the EPSRC (EP/M028100/1). Dr. F. lacoviello and T. Neville are gratefully acknowledged for technical support. P.R.S. acknowledges the support of The Royal Academy of Engineering (CIET1718/59)

\section{References}

[1] E. Vogt, B. Weckhuysen, Fluid catalytic cracking: recent developments on the grand old lady of zeolite catalysis, Chemical Society Reviews, 44 (2015) 7342-7370. 
[2] Y. Liu, F. Meirer, C.M. Krest, S. Webb, B.M. Weckhuysen, Relating structure and composition with accessibility of a single catalyst particle using correlative 3-dimensional micro-spectroscopy, Nature communications, 7 (2016) 12634.

[3] C. Perego, R. Millini, Porous materials in catalysis: challenges for mesoporous materials, Chemical Society Reviews, 42 (2013) 3956-3976.

[4] F. Meirer, D.T. Morris, S. Kalirai, Y. Liu, J.C. Andrews, B.M. Weckhuysen, Mapping metals incorporation of a whole single catalyst particle using element specific X-ray nanotomography, Journal of the American Chemical Society, 137 (2015) 102-105.

[5] F. Krumeich, J. Ihli, Y. Shu, W.-C. Cheng, J.A. van Bokhoven, Structural Changes in Deactivated Fluid Catalytic Cracking Catalysts Determined by Electron Microscopy, ACS Catalysis, 8 (2018) 4591-4599.

[6] J. García-Martínez, K. Li, G. Krishnaiah, A mesostructured Y zeolite as a superior FCC catalyst-from lab to refinery, Chemical Communications, 48 (2012) 11841-11843.

[7] A.K. Chakraborty, Phase transformation of kaolinite clay, Springer 2014.

[8] Y. Mathieu, A. Corma, M. Echard, M. Bories, Single and combined Fluidized Catalytic Cracking (FCC) catalyst deactivation by iron and calcium metal-organic contaminants, Applied Catalysis A: General, 469 (2014) 451-465.

[9] D. Wallenstein, D. Farmer, J. Knoell, C. Fougret, S. Brandt, Progress in the deactivation of metals contaminated FCC catalysts by a novel catalyst metallation method, Applied Catalysis A: General, 462 (2013) 91-99.

[10] D. Wallenstein, K. Schäfer, R. Harding, Impact of rare earth concentration and matrix modification in FCC catalysts on their catalytic performance in a wide array of operational parameters, Applied Catalysis A: General, 502 (2015) 27-41.

[11] R. Sadeghbeigi, Fluid catalytic cracking handbook: An expert guide to the practical operation, design, and optimization of FCC units, Elsevier 2012.

[12] K.M. Rambau, N.M. Musyoka, N. Manyala, J. Ren, H.W. Langmi, M.K. Mathe, Preparation of carbon nanofibers/tubes using waste tyres pyrolysis oil and coal fly ash derived catalyst, Journal of Environmental Science and Health, Part A, (2018) 1-8.

[13] B.C. Gates, Catalytic chemistry, (1991).

[14] A.T. Sipra, N. Gao, H. Sarwar, Municipal solid waste (MSW) pyrolysis for bio-fuel production: A review of effects of MSW components and catalysts, Fuel Processing Technology, 175 (2018) 131.

[15] S. Mitchell, N.-L. Michels, J. Pérez-Ramírez, From powder to technical body: the undervalued science of catalyst scale up, Chemical Society Reviews, 42 (2013) 6094-6112.

[16] J. Rouquerol, D. Avnir, C. Fairbridge, D. Everett, J. Haynes, N. Pernicone, J. Ramsay, K. Sing, K. Unger, Recommendations for the characterization of porous solids (Technical Report), Pure and Applied Chemistry, 66 (1994) 1739-1758.

[17] Y. Shu, A. Travert, R. Schiller, M. Ziebarth, R. Wormsbecher, W.-C. Cheng, Effect of ionic radius of rare earth on USY zeolite in fluid catalytic cracking: Fundamentals and commercial application, Top Catal, 58 (2015) 334-342.

[18] W.-c. Yang, Handbook of fluidization and fluid-particle systems, CRC press 2003.

[19] M. Milina, S. Mitchell, P. Crivelli, D. Cooke, J. Pérez-Ramírez, Mesopore quality determines the lifetime of hierarchically structured zeolite catalysts, Nature Communications, 5 (2014) 3922.

[20] B. Xu, S. Bordiga, R. Prins, J.A. van Bokhoven, Effect of framework Si/Al ratio and extraframework aluminum on the catalytic activity of Y zeolite, Applied Catalysis A: General, 333 (2007) 245-253.

[21] R. Beyerlein, C. Choi-Feng, J. Hall, B. Huggins, G. Ray, Effect of steaming on the defect structure and acid catalysis of protonated zeolites, Top Catal, 4 (1997) 27-42.

[22] J. Ihli, R.R. Jacob, M. Holler, M. Guizar-Sicairos, A. Diaz, J.C. Da Silva, D.F. Sanchez, F. Krumeich, D. Grolimund, M. Taddei, A three-dimensional view of structural changes caused by deactivation of fluid catalytic cracking catalysts, Nature communications, 8 (2017) 809. 
[23] F. Meirer, S. Kalirai, J.N. Weker, Y. Liu, J. Andrews, B. Weckhuysen, Agglutination of single catalyst particles during fluid catalytic cracking as observed by X-ray nanotomography, Chemical Communications, 51 (2015) 8097-8100.

[24] A. Psarras, E. Iliopoulou, L. Nalbandian, A. Lappas, C. Pouwels, Study of the accessibility effect on the irreversible deactivation of FCC catalysts from contaminant feed metals, Catalysis Today, 127 (2007) 44-53.

[25] O. Bayraktar, E.L. Kugler, Visualization of the equilibrium FCC catalyst surface by AFM and SEM-EDS, Catal Lett, 90 (2003) 155-160.

[26] M. Argyle, C. Bartholomew, Heterogeneous catalyst deactivation and regeneration: a review, Catalysts, 5 (2015) 145-269.

[27] F. Meirer, S. Kalirai, D. Morris, S. Soparawalla, Y. Liu, G. Mesu, J.C. Andrews, B.M. Weckhuysen, Life and death of a single catalytic cracking particle, Science advances, 1 (2015) e1400199.

[28] J.D. Grunwaldt, J.B. Wagner, R.E. Dunin-Borkowski, Imaging catalysts at work: a hierarchical approach from the macro-to the meso-and nano-scale, ChemCatChem, 5 (2013) 62-80.

[29] I.L. Buurmans, J. Ruiz-Martínez, W.V. Knowles, D. Van Der Beek, J.A. Bergwerff, E.T. Vogt, B.M. Weckhuysen, Catalytic activity in individual cracking catalyst particles imaged throughout different life stages by selective staining, Nature chemistry, 3 (2011) 862.

[30] V. Piergrossi, C. Fasolato, F. Capitani, G. Monteleone, P. Postorino, P. Gislon, Application of Raman spectroscopy in chemical investigation of impregnated activated carbon spent in hydrogen sulfide removal process, International Journal of Environmental Science and Technology, 16 (2019) 1227-1238.

[31] A. Demirbas, H. Alidrisi, M.A. Balubaid, API Gravity, Sulfur Content, and Desulfurization of Crude Oil, Petroleum Science and Technology, 33 (2015) 93-101.

[32] N. Ltd., UK Department for Transport announces biofuel reforms, Biodiesel Magazine, 2017. [33] P. Lettieri, D. Newton, J.G. Yates, Homogeneous bed expansion of FCC catalysts, influence of temperature on the parameters of the Richardson-Zaki equation, Powder Technology, 123 (2002) 221-231.

[34] P. Lettieri, S. Brandani, J. Yates, D. Newton, A generalization of the Foscolo and Gibilaro particle-bed model to predict the fluid bed stability of some fresh FCC catalysts at elevated temperatures, Chemical engineering science, 56 (2001) 5401-5412.

[35] P. Lettieri, D. Newton, J. Yates, High temperature effects on the dense phase properties of gas fluidized beds, Powder Technology, 120 (2001) 34-40.

[36] Y. Zhang, P.T. Williams, Carbon nanotubes and hydrogen production from the pyrolysis catalysis or catalytic-steam reforming of waste tyres, Journal of Analytical and Applied Pyrolysis, 122 (2016) 490-501.

[37] Y. Zhang, M.A. Nahil, C. Wu, P.T. Williams, Pyrolysis-catalysis of waste plastic using a nickel-stainless-steel mesh catalyst for high-value carbon products, Environmental technology, 38 (2017) 1-9.

[38] C. Wu, P.T. Williams, Investigation of coke formation on Ni-Mg-Al catalyst for hydrogen production from the catalytic steam pyrolysis-gasification of polypropylene, Applied Catalysis B: Environmental, 96 (2010) 198-207.

[39] Y. Zhang, M.A. Nahil, C. Wu, P.T. Williams, Pyrolysis-catalysis of waste plastic using a nickelstainless steel mesh catalyst for high value carbon products, Environmental Technology, (2017) $1-27$.

[40] Y. Zhang, P.T. Williams, Carbon nanotubes and hydrogen production from the pyrolysis catalysis or catalytic-steam reforming of waste tyres, Journal of Analytical and Applied Pyrolysis, (2016).

[41] Y. Zhang, C. Wu, M.A. Nahil, P. Williams, High-value resource recovery products from waste tyres, Proceedings of the Institution of Civil Engineers - Waste and Resource Management, 169 (2016) 137-145. 
[42] W. Fang, C. Pirez, M. Capron, S. Paul, T. Raja, P.L. Dhepe, F. Dumeignil, L. JalowieckiDuhamel, Ce-Ni mixed oxide as efficient catalyst for $\mathrm{H} 2$ production and nanofibrous carbon material from ethanol in the presence of water, RSC Advances, 2 (2012) 9626-9634.

[43] M.S. Dresselhaus, G. Dresselhaus, A. Jorio, A.G. Souza Filho, R. Saito, Raman spectroscopy on isolated single wall carbon nanotubes, Carbon, 40 (2002) 2043-2061.

[44] A. Carrero, J.A. Calles, A.J. Vizcaíno, Effect of $\mathrm{Mg}$ and $\mathrm{Ca}$ addition on coke deposition over $\mathrm{Cu}-\mathrm{Ni} / \mathrm{SiO} 2$ catalysts for ethanol steam reforming, Chemical Engineering Journal, 163 (2010) 395-402.

[45] R.A. DiLeo, B.J. Landi, R.P. Raffaelle, Purity assessment of multiwalled carbon nanotubes by Raman spectroscopy, Journal of Applied Physics, 101 (2007) 064307.

[46] A.C. Ferrari, J. Robertson, Raman spectroscopy of amorphous, nanostructured, diamondlike carbon, and nanodiamond, Philosophical Transactions of the Royal Society of London A: Mathematical, Physical and Engineering Sciences, 362 (2004) 2477-2512.

[47] M.W. Smith, I. Dallmeyer, T.J. Johnson, C.S. Brauer, J.-S. McEwen, J.F. Espinal, M. GarciaPerez, Structural analysis of char by Raman spectroscopy: Improving band assignments through computational calculations from first principles, Carbon, 100 (2016) 678-692.

[48] A.C. Ferrari, J. Robertson, Raman spectroscopy of amorphous, nanostructured, diamondlike carbon, and nanodiamond, Philosophical Transactions of the Royal Society of London. Series A: Mathematical, Physical and Engineering Sciences, 362 (2004) 2477-2512.

[49] A.C. Ferrari, J. Robertson, Interpretation of Raman spectra of disordered and amorphous carbon, Physical review B, 61 (2000) 14095.

[50] J. Hsieh, Computed tomography: principles, design, artifacts, and recent advances, SPIE Bellingham, WA, 2009.

[51] B. Münch, L. Holzer, Contradicting geometrical concepts in pore size analysis attained with electron microscopy and mercury intrusion, Journal of the American Ceramic Society, 91 (2008) 4059-4067.

[52] S. Brunauer, P.H. Emmett, E. Teller, Adsorption of gases in multimolecular layers, J. Am. Chem. Soc, 60 (1938) 309-319.

[53] C.H. Bartholomew, R.J. Farrauto, Hydrogen production and synthesis gas reactions, Fundamentals of Industrial Catalytic Processes, Second Edition, (2006) 339-486.

[54] S. Gregg, K. Sing, Adsorption, surface area and porosity. Academic Press, London, Adsorption, surface area and porosity. 2nd ed. Academic Press, London., (1982) -.

[55] J.C. Acomb, C. Wu, P.T. Williams, The use of different metal catalysts for the simultaneous production of carbon nanotubes and hydrogen from pyrolysis of plastic feedstocks, Applied Catalysis B: Environmental, 180 (2016) 497-510.

[56] M. Dierolf, A. Menzel, P. Thibault, P. Schneider, C.M. Kewish, R. Wepf, O. Bunk, F. Pfeiffer, Ptychographic X-ray computed tomography at the nanoscale, Nature, 467 (2010) 436.

[57] G. Yaluris, W.-C. Cheng, M. Peters, L. McDowell, L. Hunt, Mechanism of fluid cracking catalysts deactivation by Fe, Studies in Surface Science and Catalysis, Elsevier2004, pp. 139163.

[58] K.S. Sing, Reporting physisorption data for gas/solid systems with special reference to the determination of surface area and porosity (Recommendations 1984), Pure and applied chemistry, 57 (1985) 603-619.

[59] Z. ALOthman, A review: fundamental aspects of silicate mesoporous materials, Materials, 5 (2012) 2874-2902.

[60] R. Wang, S. Sang, D. Zhu, S. Liu, K. Yu, Pore characteristics and controlling factors of the Lower Cambrian Hetang Formation shale in Northeast Jiangxi, China, Energy Exploration \& Exploitation, 36 (2018) 43-65.

[61] L. Shao, L. Liu, H. Wen, Y. Li, W. Zhang, M. Li, Characteristics and influencing factors of nanopores in the Middle Jurassic Shimengou shale in well YQ-1 of the northern Qaidam Basin, Earth Science Frontiers, 23 (2016) 164-173. 
[62] J. Broekhoff, Mesopore determination from nitrogen sorption isotherms: Fundamentals, scope, limitations, Studies in Surface Science and Catalysis, Elsevier1979, pp. 663-684.

[63] S. Lowell, J.E. Shields, M.A. Thomas, M. Thommes, Characterization of porous solids and powders: surface area, pore size and density, Springer Science \& Business Media 2012. 